\title{
Systematizing a Consumer's Needs on Shoes Design by Construction of HOQ
}

\author{
Jae Cheel Kang ${ }^{1}$, Dong Choon Lee ${ }^{2}$, Joung Hoon $\mathrm{Sim}^{2}$, Byung Gun Lee ${ }^{3}$ \\ ${ }^{1}$ Department of Industrial Design, Dong Eui University, Busan, Korea \\ kang@deu.ac.kr \\ ${ }^{2}$ Department of Systems Engineering, Dong-A University, Busan, Korea \\ dclee@dau.ac.kr, ihsim@donga.ac.kr \\ ${ }^{3}$ Division of Health Sports, Dong Seo University, Busan, Korea \\ bglee@dongseo.ac.kr
}

\begin{abstract}
The purpose of this study was to understand the customer's needs and to construct house of quality(HOQ) for shoes using the customer's needs and quality function deployment(QFD). The customer's needs was measured by a questionnaire and analyzed by the structural equation model(SEM). The engineering characteristics of HOQ was analyzed by the analytic hierarchy process(AHP). The results of this study showed that the HOQ for shoes was effected by the customer's needs.
\end{abstract}

Keywords: shoes, customer's needs, quality function deployment (QFD)

\section{Introduction}

Exponential changes of international competitiveness incite the competition among enterprises and require quality satisfaction for the varieties of customers' needs. These show that production-oriented engineering, which is the form of the previous product engineering, is changed to product-oriented engineering or selling-oriented engineering that reflected customers' needs. The current of customer-oriented product engineering came to lead customers to choose products. Therefore, enterprises should focus on their customers' needs and actualize the management for customer satisfaction[1].

Especially, shoes products are, these days, required to be manufactured for not only protection of foot but also functional purposes which customers ask for. Moreover, according to the fact that sport becomes a part of our lives and the customers' tastes of design are enhanced, the customer-oriented engineering is extremely demanded. Thus, the stream of the shoe study is being changed from the study which depends on the shoe size to the ergonomic study which considers the shoe design. Based on this, diverse studies like quality function deployment are in progress not to simply offer the guide line of shoe design but to satisfy customers' external and internal needs[2][3].

For the customer-oriented shoe engineering, first of all, investigating customers' needs for shoes is surely necessary. As customers' needs is remarkably important information for design, the effective realization of this is directly linked to successful products through the customer satisfaction in the market. Hence, customers' needs should be represented as a useful form which designers and producers can utilize when manufacturing shoes[4]. However, customers' needs is primarily collected and provided from the position of marketing and human sensibility ergonomics, and the character and the purpose of using it are a lot abstract and have the limit of the approach of human sensibility ergonomics. For the reason, there are some difficult points in the properties of products and the organic composition of components. And then, designers, who concern in materializing products, have difficulties in using it effectively. From all of these, the process of reinterpretating the customers' needs as a designer-oriented language, that is design-oriented information, is necessary[5].

Therefore, this study derived not only diverse factors of customers' needs which is required to purchase shoes or the main cause of purchasing shoes but also the model of customers' needs of shoes from the definitions of the characteristics of shoes and human beings, and verified research models and research hypothesis through a structural equation model. Also, QFD(Quality Of Deployment) is performed through the evaluation of experts, and HOQ(House Of Quality) is constructed to satisfy customers by using every factor of the system of customers' needs and the characteristics of every quality engineering.

\section{Design and experiment of customers' needs system}

\subsection{Design of the research model}

This study excerpted important factors which influence on designing shoes, manufacturing shoes, and customers' purchasing, based on the existing study, to construct a theoretical model on the system of customers' needs of shoe products. Further more, after 
constructing the model of the system of customers' needs which influence on the customer satisfaction, based on the interviews of the employers in practical business, the important potential factors and items which influence on customer satisfaction are classified as table 1 and figure 1.

Table 1. Factors and items from the reconstruction of the system of customers' needs

\begin{tabular}{|c|c|}
\hline Trotor & I \\
\hline function 1 & $\begin{array}{l}\text { Weight(x1), Flexibility(X2), } \\
\text { Skewness(X3), Hardness(X4) }\end{array}$ \\
\hline function 2 & $\begin{array}{c}\text { Durability(X5), Ventilation(X6), } \\
\text { Cushion(X7), Fitting(X8) }\end{array}$ \\
\hline fitness & $\begin{array}{l}\text { Foot circumference compression(X9), } \\
\text { Heel compression(X10), } \\
\text { Instep compression(X11), Toe space(X12) }\end{array}$ \\
\hline $\begin{array}{c}\text { brand } \\
\text { attribute }\end{array}$ & $\begin{array}{l}\text { Brand(X16), Preference(X17), } \\
\text { High-grade(X18), Trend(X19) }\end{array}$ \\
\hline design 1 & $\begin{array}{c}\text { Color(X21), Shape(X22), Material(x23), } \\
\text { Balance(X24) }\end{array}$ \\
\hline design 2 & $\begin{array}{l}\text { Attraction(X26), Harmony (X27), } \\
\text { Distinction of design(X28) }\end{array}$ \\
\hline satisfy & Satisfaction of product $(\mathrm{y} 1, \mathrm{y} 2)$ \\
\hline
\end{tabular}

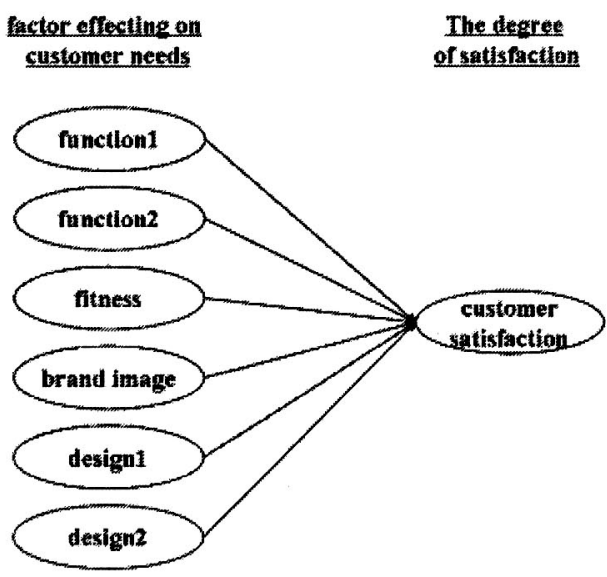

Figure 1. Modified research design 1

\subsection{Experiment on research model}

The measurement of research model consists of a seven-point Likert's scale using questionnaire. One point is given when every item is rarely important and seven point is given when item is very important. That means high-score items are more important for customers' purchasing shoes. The subject of the questionnaire are public shoe purchasers. The questionnaire consists of 42 items in total, 11 anthropological statistic items such as sex, age, occupation, educational background, and shoe types, and 31 items which related to the importance of shoe purchasing and the satisfaction. 281 copies were taken back. Of the subject, 116 were men and 165 were women. The average age was 28.9 years old and 28.1 years old each.

\subsection{Analysis of reliability and validity of research model}

Analysis of reliability and validity of research model is performed by using SPSS 12.0 programs and amos 4.0 programs[6][7]. First, EFA(Exploratory Factor Analysis) by oblique rotation and reliability analysis by using Chronbachs a modulus are performed to estimate unidimensionality of dependent variable of every factor. Besides, CFA(Confirmatory Factor Analysis) is carried out based on exploratory factor analysis and reliability analysis.

\subsection{Verification of research model}

On the basis of the previously presented analysis results of research model, the whole structure of research model was verified. The results of verification of research model are as follows; $\mathrm{X}^{2}=1077.473$, degree of freedom $=269,=0.000, \mathrm{GFI}=0.742, \mathrm{AGFI}=0.689$, $\mathrm{RMR}=0.318, \mathrm{NFI}=0.650$. From the criterion of the fitness index of these results, it is hard to consider this as the best model. In this study, thus, introducing modification index was necessary to improve the overall fitness of the model. And then, the new paths among function 1 , function 2 , and fitness, and among brand image, design 1 , and design 2 were found and established. The new additional path among function 1, design 1, and design 2 was established as well. Moreover, the new path among error terms was found and fitness index of the research model was modified. Based on these, the result of causal analysis and path analysis of the newly modified model is as you see the figure 2 .

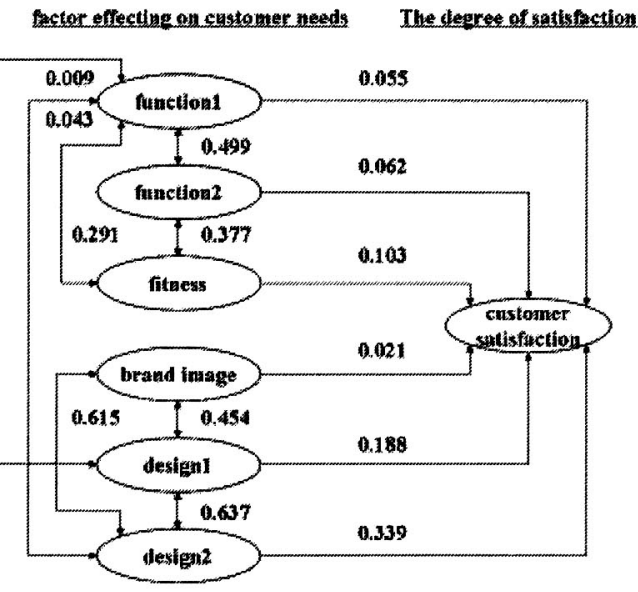

Figure 2. The path model for all subjects

\section{Construction of HOQ through QFD}

\subsection{Evaluation of the factors of $\mathrm{HOQ}$}

In this study, physical structure of layers of shoes like figure 3 is constructed through QFD to derive engineering factors in the course of constructing HOQ and relative scale of importance of every item of shoes, the sole of shoes, shoe leather, and the entire of shoes, is made up by using AHP technique based on shoe experts' 
opinions. By grouping more narrowly, the orders of it are out-sole, heel, the front of shoe leather, mid-sole, in-sole, and shoes lace. These scales of the importance showed various results according to the characteristics of each.



Figure 3. Customer satisfaction and AHP of engineering characteristics of shoes according to relative importance of design

\subsection{Construction of HOQ}

This study constructed a new HOQ which has two parameters of the QFD(engineering characteristics and customer attributes). The new HOQ takes the results of the relative scale of importance through AHP as engineering characteristics(ECs), and some elements and factors built through the customer's needs system as customer attributes(CAs). In addition, the extent of influence of engineering characteristics on the customer's needs is measured from a experts' group to investigate the relations between the two parameters of the HOQ. The HOQ, in this study, not only represents customer attributes but also includes information about the importance of customer attributes based on the customer's needs system in building the existing QFD which indicates the relation among features of products and, by extension, the HOQ in a process of shoes engineering. What is more, the HOQ is established which includes the needs system according to anthropological statistic characteristics.

\section{Conclusion}

To improve customer satisfaction and competitive power of goods, customers' demand and potential dissatisfaction should be recognized and factors of customer-oriented quality should be considered which can solve these problems. Considering that customers demand is being various, recognition of customers' needs can be a tremendously important factor. However, recognition of customers' needs, the base of in the field of footwear, merely remains as a methodology in marketing and ergonomics. On that account, reflection of shoe designers' opinions on products is realistically in a difficult situation.

Therefore, this study tried to provide the degree of customer satisfaction and HOQ which reflects engineering characteristics influence on customer satisfaction while engineering shoes through QFD approach, which considers customers' needs system and engineering characteristics of shoes. The procedure of this study was three stages, construction of customers' needs system, recognition of layered structure of engineering characteristics, drawing up HOQ. First of all, for construction of customers' needs system, a research model about important factors and items which influence on customers' needs is established and verified by using a structural equation model through questionnaire about the subject of the study. Second, the scale of relative importance is evaluated about the engineering characteristics which influence on shoe engineering using AHP analysis. At last, HOQ is constructed which takes customers' needs system as customer attributes of HOQ and takes the result of AHP analysis as engineering characteristics of $\mathrm{HOQ}$.

\section{Reference}

[1] Kim H. T. and Lee, J. C.: The Positive Study on Customer-oriented Quality Creation of FootwearFocused on Kano model and QFD, Journal of Quality Management, 30(1), 2002.

[2] Kim J. H. and Hwahng I, K.: The Positive Study on Deriving Sensitivity-oriented Engineering Factors of Footwear based on QFD, Journal of Quality Management, 32(1): 130-143, 2004

[3] Karin B. and John A: "Quality Function Deployment(QFD) - A means for developing usable products, " International Journal of Industrial Ergonomics, 18, 269-275, 1996

[4] Hwahng, J. J. and Kim, M, S.: The Study on the Development of the Process of Design Information Changes of Customers' Needs, Korea Society of Design Studies, 12(1), 1999.

[5] Uhm J. S., Kim C. S. and Kim M. S.: The Study on the Structuralization of Customers' Needs through Analysis of Sensitivity Factors, Korea Society of Design Studies, 12(1), 1999.

[6] Lee H. S. and Im J. H.: SPSS 12.0 Manual, Bubmunsa Publishing, 2005.

[7] Kim K. S: Analysis of AMOS Structural Equation Model, SPSS Academy, 2005. 